Article

\title{
Wettability Control for Correct Thermophysical Properties Determination of Molten Salts and Their Nanofluids ${ }^{\dagger}$
}

\author{
Yaroslav Grosu ${ }^{1, *(D)}$, Luis González-Fernández ${ }^{1}$ (D), Udayashankar Nithiyanantham ${ }^{1,2}$ (D) and \\ Abdessamad Faik $1, *$ (D) \\ 1 CIC Energigune, Albert Einstein, 4801510 Miñano, Spain; lgonzalez@cicenergigune.com (L.G.-F.); \\ nudayashankar@cicenergigune.com (U.N.) \\ 2 Applied Physics II Department, Faculty of Science and Technology, University of the Basque \\ Country (UPV/EHU), PO Box 644, 48080 Bilbao, Spain \\ * Correspondence: ygrosu@cicenergigune.com (Y.G.); afaik@cicenergigune.com (A.F.); \\ Tel.: +34-945-297-108 (Y.G.) \\ $+\quad$ This paper is an extended version of our paper published in 1st International Conference on Nanofluids \\ (ICNf) and the 2nd European Symposium on Nanofluids (ESNf), Castello, Spain, 26-28 June 2019.
}

Received: 13 September 2019; Accepted: 30 September 2019; Published: 2 October 2019

\begin{abstract}
Proper recording of thermophysical properties for molten salts (MSs) and molten salts based nanofluids (MSBNs) is of paramount importance for the thermal energy storage (TES) technology at concentrated solar power (CSP) plants. However, it is recognized by scientific and industrial communities to be non-trivial, because of molten salts creeping (scaling) inside a measuring crucible or a sample container. Here two strategies are proposed to solve the creeping problem of MSs and MSBNs for the benefit of such techniques as differential scanning calorimetry (DSC) and laser flash apparatus (LFA). The first strategy is the use of crucibles with rough inner surface. It was found that only nanoscale roughness solves the creeping problem, while micron-scale roughness does not affect the wetting phenomena considerably. The second strategy is the use of crucible made of or coated with a low-surface energy material. Both strategies resulted in contact angle of molten salt higher than $90^{\circ}$ and as a result, repeatable measurements in correspondence to the literature data. The proposed methods can be used for other characterization techniques where the creeping of molten salts brings the uncertainty or/and unrepeatability of the measurements.
\end{abstract}

Keywords: molten salt; thermophysical properties determination; wetting; differential scanning calorimetry; laser flash apparatus

\section{Introduction}

Molten salts are commonly used as a storage material at Concentrated Solar Power (CSP) plants [1,2], where their amount is of the order of thousands of tons [3-5]. For example, at GEMASOLAR CSP plant 8500 tons of Solar salt is used [3], at Andasol-1 CSP plant it is 28,500 tons [4] and at Solana CSP plant it is 125,000 tons [5]. Currently, so-called Solar salt $\left(60-40 \mathrm{wt} \%\right.$ of $\left.\mathrm{NaNO}_{3}-\mathrm{KNO}_{3}\right)$ is used most often. Hence, knowing the precise values of their heat capacity $(\mathrm{Cp})$ and thermal conductivity $(\lambda)$ is of the highest importance. However, it is recognized by the scientific and industrial communities to be very complicated, as reflected by the discrepancy of the published results. The same problem stands for molten salts based nanofluids [6]. In the last few years, the quality and accuracy of the thermophysical properties data of inorganic salts have been widely debated. This is due to the discrepancy of the published experimental results, obtained by different groups using different techniques [6]. As example, a round-robin test was performed in 2017 to measure Cp of the Solar salt by 11 institutions [7]. 
In order to get reliable values from such widely used techniques as Differential Scanning Calorimetry (DSC) or Laser Flash Apparatus (LFA), the sample must be in a good contact with the crucible. However, due to strong wetting typically molten salts creep on the walls of the measuring crucible Scheme 1. This results in a non-uniform thickness and an unacceptable error of the measurement.
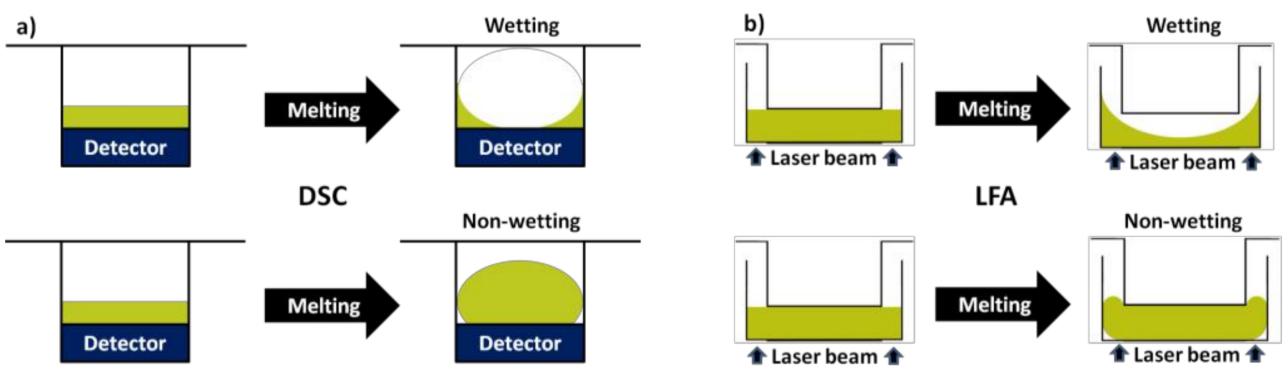

Scheme 1. Behavior of molten salt inside (a) DSC and (b) LFA crucible in case of wetting (top) and non-wetting (bottom) conditions.

The salt can be immobilized in the crucible if its quantity is large enough [8-10]. Such an approach was recently used by Muñoz-Sánchez et al. for Solar salt-based nanofluids [8]. Earlier, positive effect of larger mass in the DSC crucible on the accuracy of DSC measurements was noted by Thoms [9], and Hohne et al. [10]. However, the use of a larger mass has several important disadvantages. Firstly, due to thermal expansion of a larger quantity of molten salt, pressure builds up during the measurement in the measuring crucible. Obviously, in this case what is measured is not isobaric heat capacity (heat capacity at constant pressure). Besides, elevated pressure can lead to the leakage of the salt or even to the crucible deformation. This brings the risk of a critical damage of the equipment as a result of high corrosivity of molten salts at elevated temperature. Sometimes a hole is made in the crucible lead to prevent pressure increase. However, this can lead to the salt leakage from the overfilled crucible.

It should be noted that while wetting properties (like contact angle) of molten salts and molten salts nanofluids are widely discussed in the literature [11-13], their control to avoid creeping is rarely discussed. In particular, a round-robin test was reported in Reference [11] to identify the effect of nanoparticles doping on the contact angle of molten nitrate salt. The method of capillary rise was applied to molten carbonate salt and porous electrodes [12]. Wettability of carbon surfaces by molten chloride salts was studied in Reference [13].

In this work, we show that by using crucible made of a low-surface energy material or by decorating the interior crucible with nanoroughness increases the wetting contact angle and mitigates the wetting phenomena, which is responsible for displacement and creeping of the salt. We propose simple chemical or physical methods of introducing such roughness, which does not require special equipment and can be applied to already existing commercial measuring cells and crucibles. We demonstrated the strategy of low-surface energy material by testing several crucibles of standard design, but made of materials with low-surface energy. We believe that the proposed methodology can be extrapolated to other characterization techniques, where wetting phenomena result in molten salt displacement, such as laser flash, rheometry, etc., see Patent [14].

\section{Materials and Methods}

\subsection{Materials}

$\mathrm{NaNO}_{3}$ and $\mathrm{KNO}_{3}$ from SQM (Sociedad Química y Minera) were used in this work. These nitrates have a purity of $\geq 99 \%$, with the list of impurities given elsewhere [12]. The Solar salt was prepared from pre-dried $\mathrm{NaNO}_{3}$ and $\mathrm{KNO}_{3}$ mixed in $60: 40 \mathrm{wt} \%$ proportion. This mixture was melted at $360{ }^{\circ} \mathrm{C}$ and kept at this temperature during $6 \mathrm{~h}$, followed by grinding in an agate mortar until homogeneous fine powder was obtained. Finally, $1 \mathrm{wt} \%$ of $50 \mathrm{~nm} \mathrm{Fe}{ }_{2} \mathrm{O}_{3}$ nanoparticles from Sigma-Aldrich were 
added to the mixture and subjected to the physical shaking method described elsewhere [15]. The Solar salt was prepared in a similar way, but without adding the nanoparticles. SPEX Sample Prep 9000-series High-Energy shaker was used for this purpose for the time period of $15 \mathrm{~min}$ using a quantity of $2 \mathrm{~g}$ of the mixture in a $50 \mathrm{~mL}$ aluminum bottle.

\subsection{Differential Scanning Calorimetry (DSC)}

Heat capacity (Cp) of the salts was measured by DSC technique (TA instruments Q2500) in a ramp mode with a heating rate of $10^{\circ} \mathrm{C} / \mathrm{min}$. Sapphire and tin were used for the calibration materials. Around $10 \mathrm{mg}$ samples were measured using aluminum crucibles, hermetically closed inside the glove-box under controlled argon atmosphere. Moreover, 3 types of T-zero hermetic Al-crucibles were used:

1. As received Al-DSC crucible from the supplier.

2. Partially leached Al-DSC crucible. These crucibles were prepared as by introducing $10 \mathrm{~mL}$ of $37 \%$ $\mathrm{HCl}$ acid into the pristine non-treated Al-DSC crucible for $15 \mathrm{~min}$, followed by distilled water washing and drying at $60^{\circ} \mathrm{C}$.

3. Completely leached Al-DSC crucible was prepared the same way as the partially leached Al-DSC crucible, but by repeating the leaching procedure 5 times.

\subsection{Laser Flash Apparatus (LFA)}

Thermal diffusivity of the salts was measured by means of a Laser Flash Apparatus (Netzsch LFA 457 model). A graphite film prime over the top and bottom surfaces of the holder sample was applied aiming to increase the absorption and emission of radiation. Thermal conductivity of the nanofluids was calculated from thermal diffusivity $(\alpha)$, measured under non-equilibrium conditions, density $(\rho)$ and specific heat capacity $(C p)$, according to the following Equation $\lambda(T)=\alpha(T) \cdot \rho(T) \cdot C p(T)$. We note that in this formula the convective heat transfer is not taken into account, which in general can have an important contribution for nanofluids. This is, however, a reasonable neglection, as it is known that if Rayleigh number is less than 1400 [16] one can consider that the convection phenomenon is negligible and for the used configuration the Ra is far below 1 even with most conservative estimations. This is due to the very low thickness of the sample (below $1 \mathrm{~mm}$ ), highly viscous sample, very small temperature difference between the top and the bottom of the crucible (below $1{ }^{\circ} \mathrm{C}$ ) and very limited time of the LFA experiment.

Three types of LFA crucibles with identical design were used in this work:

1. As received PtRh-crucible from Netzsch.

2. Similar crucible, but custom-made from zinc (Zn-crucible).

3. Similar crucible, but custom-made from Stainless Steel (SS) 316-crucible. The interior of this crucible was also decorated with roughness by means of mechanical treatment.

\subsection{Scanning Electron Microscopy (SEM)}

Quanta 200 FEG SEM was used in vacuum mode with electron beam energies $10 \mathrm{kV}, 20 \mathrm{kV}$ and 30 $\mathrm{kV}$ with a Back Scattered Electron Detector (BSED) and an Everhart-Thornley Detector (ETD).

\subsection{Optical Microscope}

Carl Zeiss Axio optical microscope was used to scan the surface of the samples after the corrosion tests.

\subsection{Contact Angle}

The contact angle of molten salt on different surfaces was estimated by treating the optical images of $10 \mathrm{mg}$ drop of molten salt at $300{ }^{\circ} \mathrm{C}$. The images were obtained by Nikon D3300 digital camera. 
The images were processed by ImageJ software in order to calculate the contact angle. At least 3 experiments were performed for each surface. At least 10 images were processed for each experiment. The highest standard deviation of the measurements was not exceeding $\pm 7^{\circ}$. While such deviation is relatively high for modern equipment for contact angle measurements, it was sufficient to clearly capture the wetting-to-non-wetting transition.

\subsection{Details on the Development of Crucibles with Roughness}

In order to introduce roughness on the inner surface of the measuring crucibles electroetching, chemical etching and mechanical treatment methods were applied. The details on these methods are provided below. The crucibles were characterized by SEM and optical microscopy to identify the obtained roughness. Contact angle of molten salt on the surface of the crucibles was measured to verify whether the non-wetting condition was achieved.

\subsubsection{Electroetching}

Electroetching method was performed using an electric discharge machine ONA DATIC D360. By varying the applied voltage and the time of exposure different roughnesses were obtained (Figure 1a). Roughness in the range of $40-800 \mu \mathrm{m}$ were achieved (Table 1). It was not possible to obtain nanoscale roughness by this method. Molten salt demonstrated a contact angle below $90^{\circ}$ for all the obtained samples, therefore, the non-wetting condition was not reached.
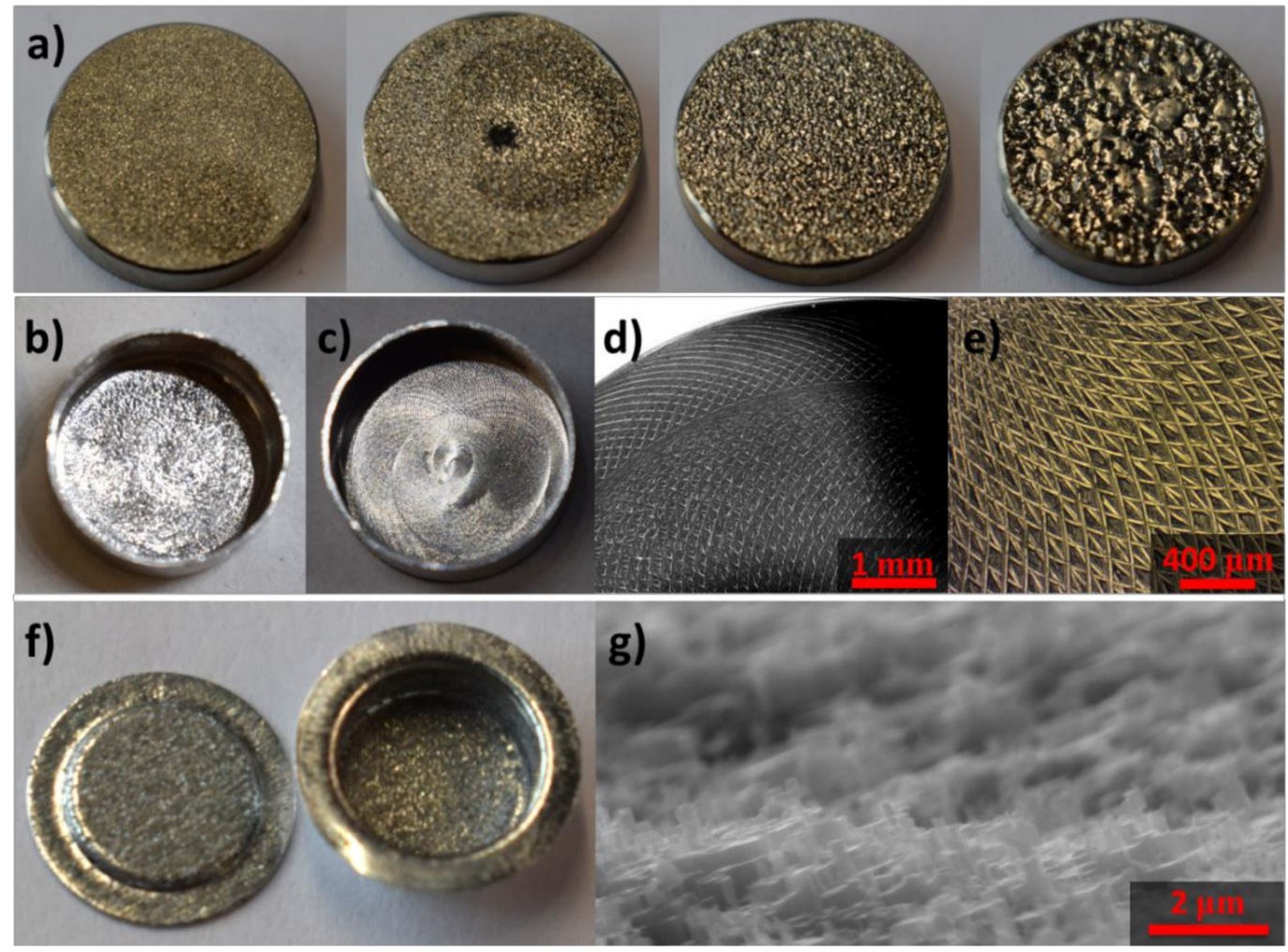

Figure 1. Optical and SEM images of different surfaces with introduced roughness. (a) SS316 with roughness obtained by electroleaching; (b) standard LFA PtRh-crucible with mechanically added roughness; (c) custom-made LFA SS316-crucible with mechanically added roughness and its (d) SEM and (e) optical images; (f) standard DSC T-zero hermetic Al-crucible with acid leaching roughness and its (g) SEM image. 
Table 1. Roughness and non-wetting condition obtained by different methods.

\begin{tabular}{ccc}
\hline Method & Scale of Roughness & Non-Wetting Condition \\
\hline Electroetching 1 & $40 \mu \mathrm{m}$ & No \\
Electroetching 2 & $110 \mu \mathrm{m}$ & No \\
Electroetching 3 & $200 \mu \mathrm{m}$ & No \\
Electroetching 4 & $800 \mu \mathrm{m}$ & No \\
Mechanical treatment Dremel & $800 \mathrm{~nm}+10-20 \mu \mathrm{m}$ & Yes \\
Mechanical treatment 2 & $700-1200 \mathrm{~nm}+100 \mu \mathrm{m}$ & Yes \\
Chemical etching & $200-400 \mathrm{~nm}+1-3 \mu \mathrm{m}$ & Yes \\
\hline
\end{tabular}

\subsubsection{Mechanical Treatment}

Mechanical treatment of the crucibles was applied in order to obtain the surface roughness (Figure 1b-e). For this purpose, common commercial polishing tools were applied. In particular, surface treatment using Dremel 4000 tool with the Engraving cutter of $2.4 \mathrm{~mm}$ resulted in a bimodal roughness, namely, with scratches of around $800 \mathrm{~nm}$ wide with large recesses of around 10-20 $\mu \mathrm{m}$ (Table 1). Such roughness resulted in a non-wetting condition for the molten salt (see Section 3.2 for more details).

\subsubsection{Chemical Etching}

The chemical etching of the crucibles was achieved by exposing their inner surface to $37 \% \mathrm{HCl}$ acid (Figure 1f). The optimization was carried out based on the exposure time, while providing fresh acid every $15 \mathrm{~min}$. The crucible prepared by 15, 30, 45, 60, 75 min exposures were examined. It was found that independently on the time of etching the roughness on the scale of 200-400 nm was obtained (Figure $1 \mathrm{~g}$ ) with occasional large rectangle pores of $1-3 \mu \mathrm{m}$ (Figure $2 \mathrm{~b}$ and Table 1 ). On the other hand, the coverage of the surface with such roughness depends on the exposure time. It was identified that etching of $75 \mathrm{~min}$ resulted in a complete coverage of the surface with the roughness, while lower time resulted in partial coverage (Figure $2 b$ ). It was identified that such roughness results in the non-wetting condition of molten salts (Figure 2c). 
a)

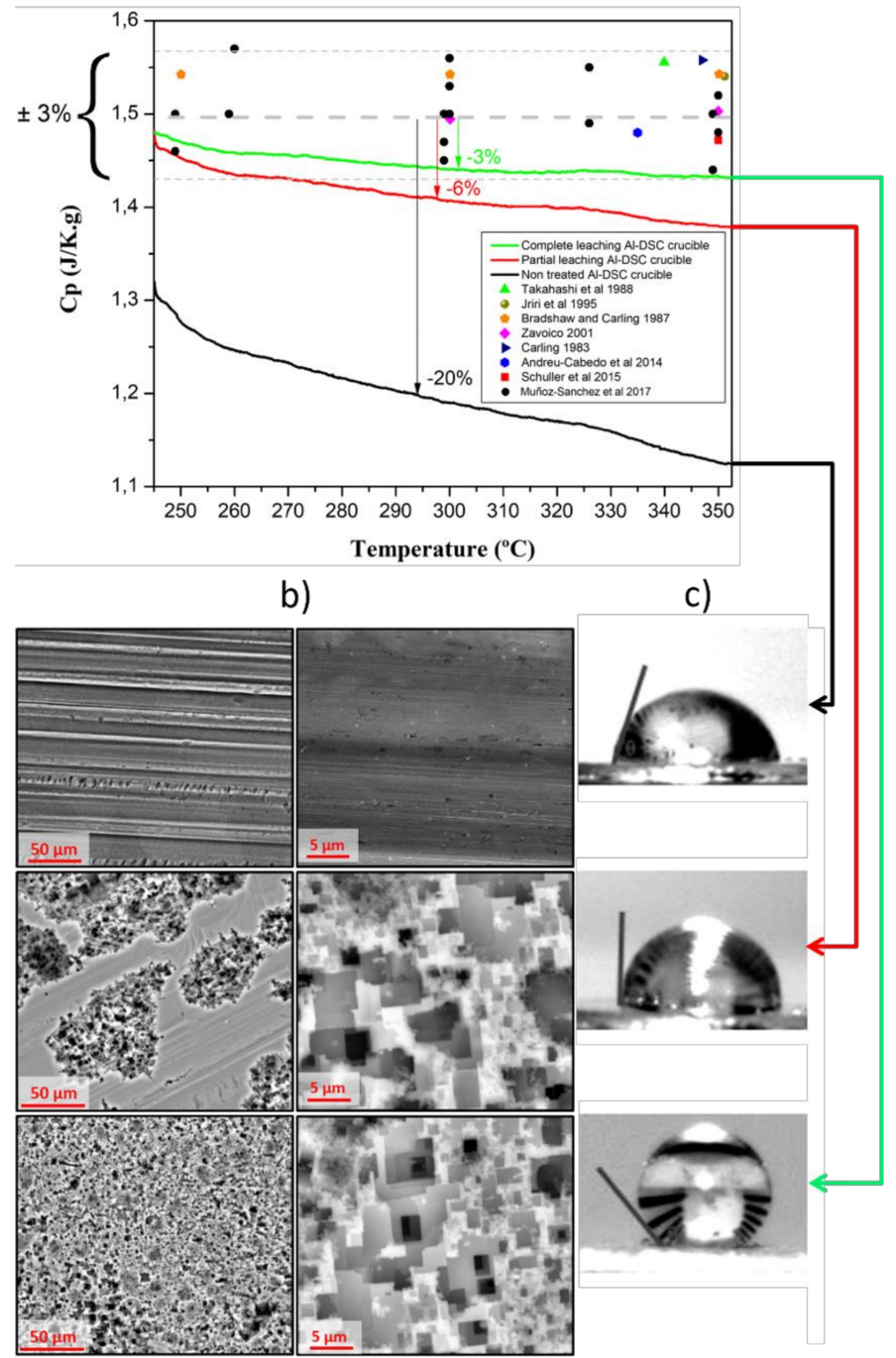

Figure 2. (a) Heat capacity of Solar salt, (b) SEM images of the crucible surface and (c) contact angle of Solar salt on the surface of the DSC crucible at $300{ }^{\circ} \mathrm{C}$ for the cases of pristine non-treated Al-DSC crucible (bottom), partially leached Al-DSC crucible (middle) and completely leached Al-DSC crucible (top).

\section{Results}

Scheme 1 demonstrates the problem of molten salt creeping inside a measuring crucible for such techniques as Differential Scanning Calorimetry (DSC) and Laser Flash Apparatus (LFA). As can be seen from Scheme 1, the wetting condition results in a molten salt creeping, eliminating the proper contact of the sample with the detector of the equipment. On the contrary, the non-wetting condition (contact angle of molten salt with the crucible is greater than $90^{\circ}$ ) would solve the creeping problem and results in a proper contact of the salt with the detector of the equipment. For most of the common materials the contact angle of molten salt is lower than $90^{\circ}$ (Figure 3). Below we explore two strategies of wettability control of molten salts for such common techniques as DSC and LFA, namely the use of crucibles with microroughness and the use of crucibles made of (or coated with) low-surface energy 
materials. For this purpose, we explored different types of roughness (Figure 1), as well as used low surface energy materials (Figure 6) for custom-made crucibles (Figure 4).

a)

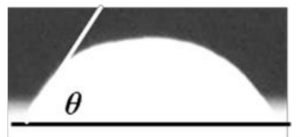

Alumina

b)

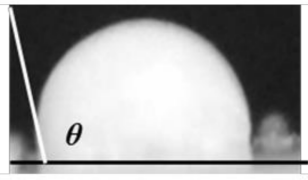

Magnesium

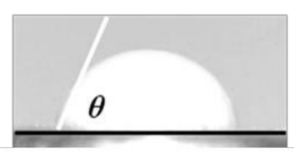

PtRh

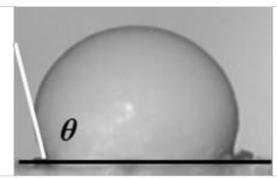

Zinc

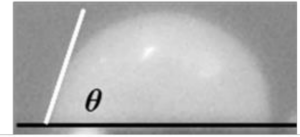

Sapphire

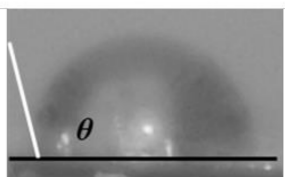

Silver

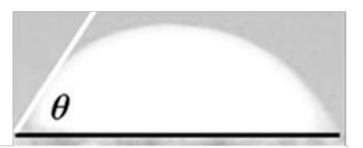

Before coating

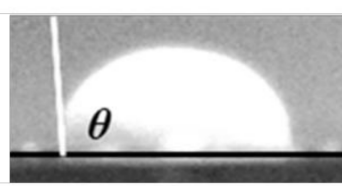

After coating

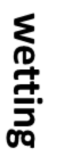

임

Figure 3. Contact angle of molten Solar salt at $300^{\circ} \mathrm{C}$ on the surface of (a) alumina, PtRh-alloy, sapphire, SS316 (wetting condition) and on the surface of (b) magnesium, zinc, silver and SS316 coated with gold (non-wetting condition).
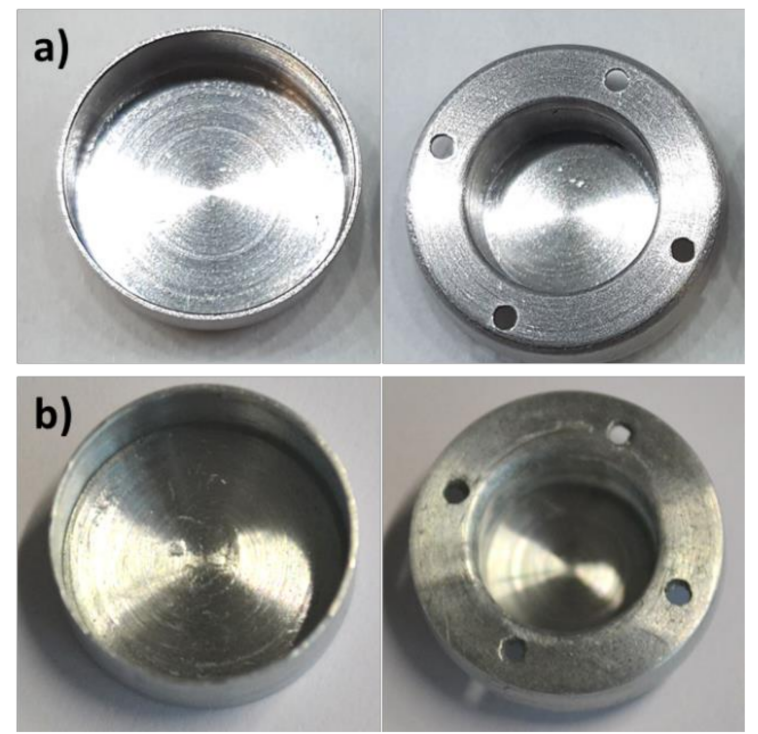

Figure 4. LFA crucible made of (a) PtRh-alloy (commercial) and (b) zinc (custom-made).

\subsection{Microroughness for Wettability Control of Molten Salts}

Surface roughness considerably affects the contact angle of a liquid resting on it [17-19]. In fact, introduction of microroughness is among one of the common methods to create super-lyophobic surfaces [17-19] surfaces, which are non-wetted by most of the liquids (contact angle more than $90^{\circ}$ ). Hence, introducing the surface roughness on the interior of the DSC or LFA crucibles can potentially mitigate the creeping problem.

In order to test such approach, different types of roughness were fabricated (Figure 1) and tested in terms of wetting properties with molten salts. First, we found that electroetching of stainless-steel materials (Figure 1a) results in a roughness, which does not bring the non-wetting condition for molten nitrate salt. Different roughness was obtained depending on the applied voltage and exposure time (Figure 1a), however, none of them resulted in the roughness capable of improving the wetting properties of molten nitrate salt. The main reason for such results was the absence of nanoroughness (while macroscopic roughness was obtained instead). On the contrary, nanoroughness was obtained by mechanical means by applying standard carving and polishing tools (Figure 1b,c). Optical and scanning electron microscopy (Figure 1d,e) confirmed the formation of microroughness, while the contact angle estimation (Figure $5 b$ ) clearly demonstrated the transition from wetting to non-wetting 
condition for the SS316 crucibles. Table 1 summarizes the relation between obtained roughness and wetting conditions.
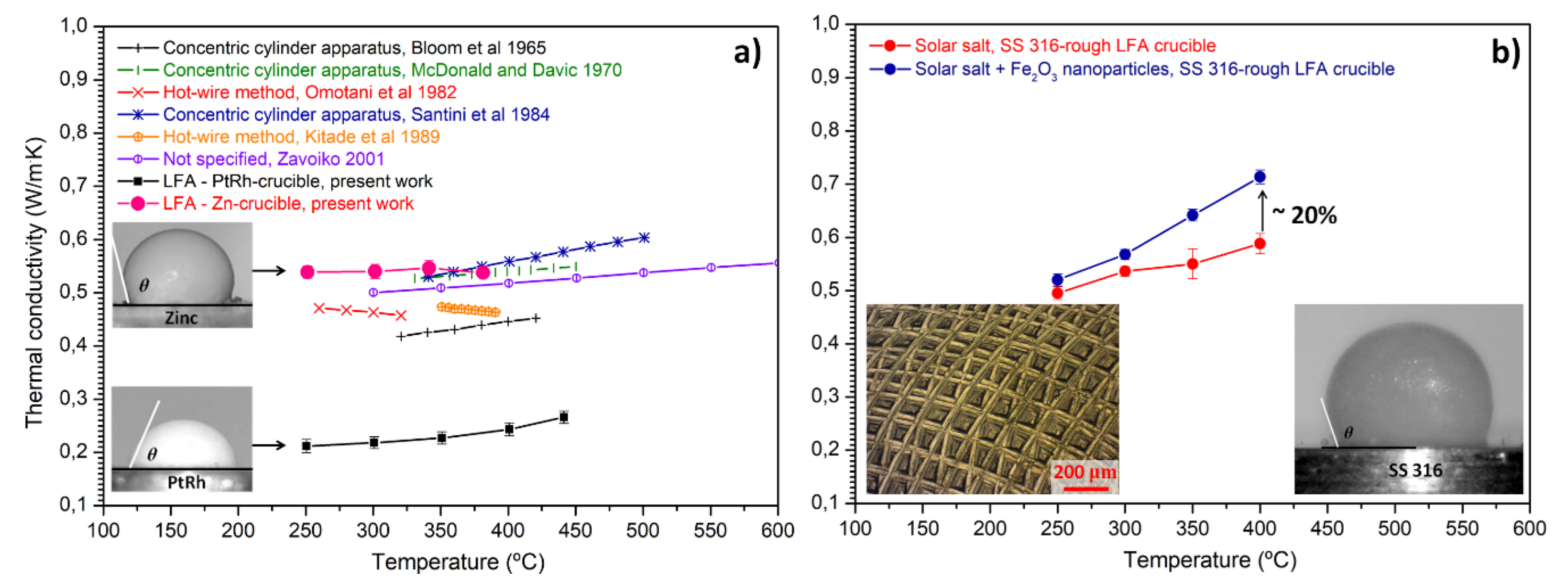

Figure 5. (a) Thermal conductivity of Solar salt measured by LFA using PtRh-and Zn-crucibles; Inserts: contact angles of Solar salt on the surface of the PtRh-and Zn-LFA crucibles. (b) Thermal conductivity of Solar salt and Solar salt-based nanofluid measured by LFA using rough SS 316-crucible; Inserts: contact angle of Solar salt on the surface of SS 316 crucible and optical image of the surface of SS 316 crucible.

For the standard T-zero hermetic Al-crucibles used for DSC analysis the acid leaching was found to be the most appropriate (Figure 1f). After the leaching, the inner surfaces of the DSC crucibles were decorated with a well-formed microroughness (Figure 1g).

Cp measurements for Solar salt are gathered in Figure 2. Al-crucibles with different roughness were used for these experiments. A clear correlation between surface roughness (Figure 2b), molten salt contact angel (Figure 2c) and Cp values (Figure 2a) was obtained. In particular, nanoroughness was obtained by acid leaching the surface of aluminum (Figure 2b). Such roughness strongly affects the contact angle of the molten salt (Figure 2c). It can be seen that, if the recommended by the supplier weight of the salt is used $(10 \mathrm{mg})$, the use of the pristine non-treated Al-crucible deviate considerably from the values reported in the literature (Figure 2a). On the other hand, the deviation of the $\mathrm{Cp}$ values from the literature are no more than 3\% when rough Al-crucible is used [7,20-26]. Partial roughness results in the values of $\mathrm{Cp}$, which are between the cases of pristine and completely rough crucibles. One can also note, that when the pristine crucible is used, the $\mathrm{Cp}$ values decreases with temperature, apparently, due to the gradual creeping of the salt. In fact, $\mathrm{Cp}$ was found to decrease with each heating-cooling cycle. On the contrary, the slope of $\mathrm{Cp}$ is almost absent for the case of completely leached crucible (Figure 2a).

Similarly, it was found that the use of standard LFA PtRh-crucible for the recommended amount of Solar salt, results in values of thermal conductivity unacceptably lower as compared to the literature data (Figure 5a). On the other hand, the use of rough SS 316-crucible for LFA technique (Figure 1c-e) results in values of thermal conductivity for Solar salt in agreement with the literature (Figure $5 b$ ) and enhanced thermal conductivity for \{Solar salt $+50 \mathrm{~nm} \mathrm{Fe}{ }_{2} \mathrm{O}_{3}$ nanoparticles\} nanofluid as expected from the previous studies [6] Figure 5b. Such improvement correlated with the increase of the contact angle due to the introduced microroughness (Figure $5 b$ ).

It should be noted, that the observed wetting-to-non-wetting transition is not a trivial effect. In particular, a generally accepted Wenzel's model [27] predicts that roughness increases the observable contact angle $\theta_{W}$ only in case the Young's contact angle on a smooth surface is greater than $\theta_{Y}>90^{\circ}$, while it reduces the observable contact angle $\theta_{W}$, if $\theta_{Y}<90^{\circ}$ according to Equation (1).

$$
\cos \theta_{W}=r \cos \theta_{Y}
$$


where $r$ is the roughness factor defined as the ratio of actual surface area over the projected surface area (basically the area without the roughness).

The contact angle of the molten nitrate salt is below $90^{\circ}$ on the smooth surfaces of aluminum (Figure 2c, top), PtRd (Figure 5a, insert) and SS316. Therefore, according to the Wenzel's model, roughness is expected to reduce the contact angle and enforce the creeping problem even more. This is in striking contrast to the observations, from which it is clearly seen that the contact angle was considerably increased due to the roughness (Figure 2c, bottom and Figure 5b, insert).

The explanation of the described controversy can be found within the Cassie-Baxter model [28]. This model predicts that non-wetting is enforced because air (or any other gas) is trapped inside the roughness (Equation (2)).

$$
\cos \theta_{C B}=r_{f} f \cos \theta_{Y}+f-1
$$

where $\theta_{C B}$ is the apparent contact angle according to the Cassie-Baxter model, $r_{f}$ is the roughness factor of the wetted area, $f$ is the area fraction of the projected wet area.

Generally, the Cassie-Baxter model is applied only to the cases when $\theta_{Y}>90^{\circ}$; however, it was hypothesized by Herminghaus that given the appropriate topology air-trapping can lead to the increased non-wetting (contact angle) even on surfaces with $\theta_{Y}<90^{\circ}$ [17]. This was later demonstrated experimentally for nanoporous gold surfaces [29] and for polycaprolactone nanopits [30]. We suggest that similar effect if observed in this work. Moreover, the preservation of the metastable state of entrapped gas inside the roughness is more probable in the case of molten salts as compared to the water, due to their much higher viscosity. As example, in our previous work it was demonstrated that the entrapped bubbles of air can remain in the molten salts based nanofluids for the periods of days depending on temperature [15,31], which is much longer than expected time of the DSC or LFA experiments.

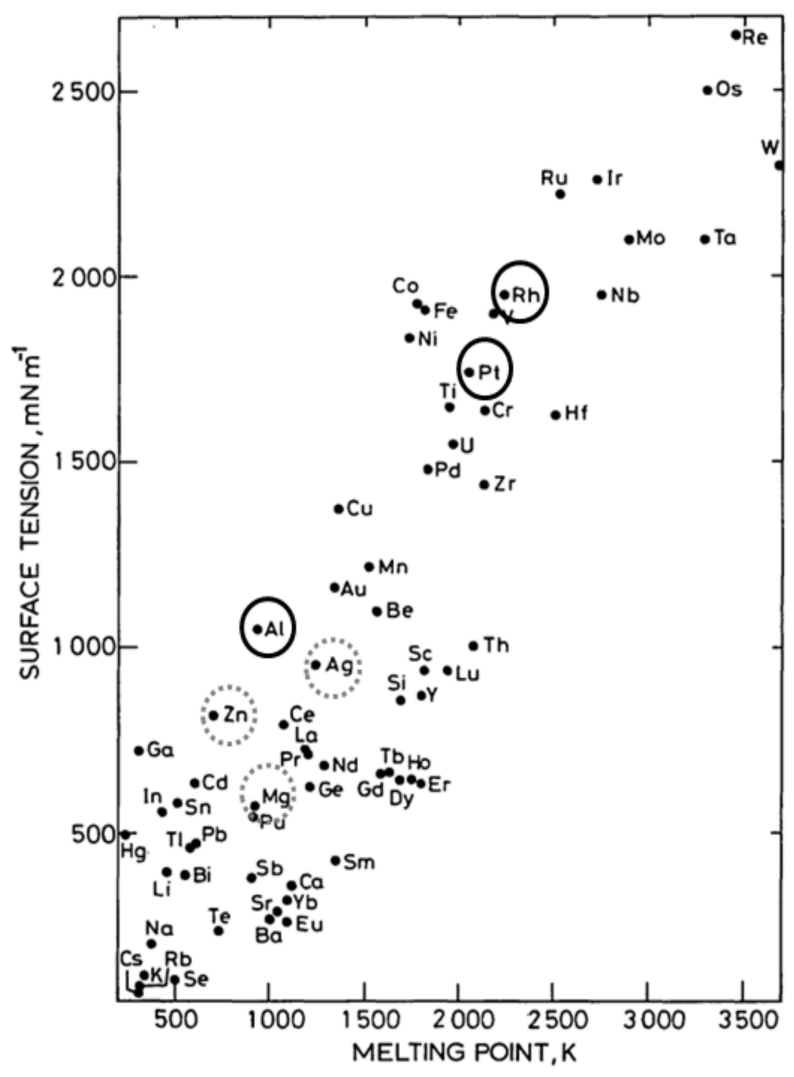

Figure 6. Surface tension of molten metals depending on their melting temperature [32]. 
Assuming that the hypothesis regarding the Cassie-Baxter state is true, one can use Equation (2) to estimate the effect of roughness on the contact angle and compare it with the experimental values. The parameters $f$ and $r_{f}$ can be estimated from the SEM characterization of the rough surfaces, assuming that there is no penetration of the salt into the pores. For the calculation we take $\theta_{Y}$ based on the contact angle measurements made on the pristine (smooth) surfaces of the crucibles. The results are summarized in Table 2. It can be seen that Equation (2) predicts the transition to the non-wetting condition $\left(\theta_{C B}>90^{\circ}\right)$ in all the cases. In general, the model underestimates the values of the contact angle as compared to the experiment. We, however, note that due to the number of assumptions described above and relatively large error both for contact angle measurements as well as $f$ and $r_{f}$ determination, such comparison is done more for the qualitative prediction of the wetting-to-non-wetting transition, rather than for the qualitative comparison. Nevertheless, it gives a clear guidance for the optimization of the proposed method. Namely, the crucibles with smaller ratio between the surface exposed to the molten salt and the projected surface of the crucible, are expected to give more pronounced effect on the contact angle and, hence, are better for solving the creeping problem.

Table 2. Experimental and calculated values of the contact angles on the surfaces of different crucibles.

\begin{tabular}{cccccc}
\hline & $\begin{array}{c}\text { Experiment } \\
\text { Smooth }\end{array}$ & $\begin{array}{c}\text { Experiment } \\
\text { Rough }\end{array}$ & $\begin{array}{c}\text { Calculated } \\
\text { Rough }\end{array}$ & $\boldsymbol{r}_{f}$ & $f$ \\
\hline Al & 71 & 128 & 118 & 4.8 & 0.21 \\
PtRd & 77 & 117 & 108 & 2.2 & 0.46 \\
SS316 & 58 & 110 & 91 & 2.2 & 0.45 \\
\hline
\end{tabular}

\subsection{Surface Energy for Wettability Control of Molten Salts}

The non-wetting condition for molten salt can also be reached by the use of low-surface energy materials for the measuring crucible. In particular, we found that for molten Solar salt at $300{ }^{\circ} \mathrm{C}$ the contact angle with gold surface is around $90^{\circ}$ Figure $3 \mathrm{~b}$. This means that for all the materials with surface energy lower than that of gold, the contact angle of molten Solar salt at $300^{\circ} \mathrm{C}$ is expected to be higher than $90^{\circ}$. This was demonstrated for the surfaces of magnesium, zinc and silver, Figure $3 \mathrm{~b}$. On the contrary, for all the materials with surface energy above the one of gold, the contact angle is expected to be below $90^{\circ}$. This was demonstrated for aluminum, PtRh-alloy, sapphire and stainless steel, Figure 3a. While surface energy may not be reported for all the materials due to complexity of such measurement, one can address more common property surface tension of metal at its melting point, which correlates with surface energy of this metal in a solid state. From Figure 6 [32] one can see that apart from magnesium, zinc and silver, there is a wide range of materials with surface tension lower than that of gold. In general, all those materials are expected to result in a contact angle of molten Solar salt higher than $90^{\circ}$. However, it is evident that metals with lower surface energy possess lower melting point, which limits their operational temperature range. Apart from lower melting temperature, one needs to take into account the possible corrosion issues.

Based on the analysis presented above a Zn-crucible for LFA was constructed using similar design as a standard PtRh-crucible provided by the supplier of the LFA equipment Figure 4. It can be seen that the use of Zn-crucible with low surface energy for LFA technique results in values of thermal conductivity, which is in good agreement with the literature (Figure 5a) [23,33-37]. On the contrary, much lower values are obtained when as received PtRh-crucible was used. The effect of the low surface energy of zinc on the contact angle of molten Solar salt is demonstrated in the inserts of Figure 5a, where the contact angle of molten Solar salt is below $90^{\circ}$ for PtRh-crucible, while it is above $90^{\circ}$ for $\mathrm{Zn}$-crucible. It should be noted that the strategy of using low-surface energy materials for measuring crucibles can be easily adapted to a wide range of crucibles, as it does not requires a design modification, but it can be simply realized by coating an existing crucible with a low-surface energy material, like gold (see Figure 3, as an example). 
In summary, it can be noted that the use of both strategies (nanoroughness and low-surface energy material) results in a non-wetting condition of the molten salt in the measuring crucibles. Such approach can be used for techniques other than DSC and LFA to deal with undesired wetting phenomenon. One can consider, as an example, the parallel plate rheometer, where according to the standard protocol all the gap between the parallel plates must be completely filled by the sample. If strong wetting takes place, a negative meniscus is formed, preventing the proper protocol execution. Therefore, reaching the non-wetting condition (positive meniscus) would have a positive effect for such technique [38].

\section{Conclusions}

Two strategies for controlling the wetting (creeping) of molten salts inside a measuring crucible were proposed in this work for the benefit of such widely used techniques as Differential Scanning Calorimetry (DSC) and Laser Flash Apparatus (LFA).

The first strategy suggests the use of crucibles with nanoroughness. Such roughness strongly increases the contact angle of a molten salt, preventing its creeping in the crucible. The proposed approach was tested using aluminum DSC crucibles by decorating their interior with nanoroughness achieved by acid leaching. LFA crucibles made of SS 316 with mechanically obtained roughness were also used. It was demonstrated that only nanoscale roughness results in a non-wetting condition for the molten salt, while micron-scale roughness did not considerably affect the contact angle of the molten salt. The main advantage of this method is that it can be chemically or physically applied to existing (commercial) crucibles, which ultimately results in a wide range of materials with proper compatibility and operational temperature range.

The second strategy implies the use of a crucible made of a low-surface energy material. This ultimately results in higher contact angle values. Zinc was used as a low-surface energy material to construct LFA crucibles and to prove the concept. The main advantage of this method is that no crucible design modifications are required. Moreover, it can be adapted to a wide range of measuring crucible by simply coating the existing crucible with a low-surface energy material.

The proposed strategies allowed recording the values of heat capacity and thermal conductivity of molten Solar salt in accordance with the literature. The proposed approach can be extended for the benefit of characterization techniques where displacement and creeping of molten salts bring an unacceptable error to the measurements.

\section{Patents}

There is one patent resulting from the work reported in this manuscript, namely, Reference [14].

Author Contributions: All authors contributed equally.

Funding: This research received no external funding.

Acknowledgments: This investigation is a contribution to the COST (European Cooperation in Science and Technology) Action CA15119: Overcoming Barriers to Nanofluids Market Uptake (NanoUptake). Y.G. acknowledges the EU COST Action CA15119: Overcoming Barriers to Nanofluids Market Uptake for financial support in the participation of the 1st International Conference on Nanofluids (ICNf) and the 2nd European Symposium on Nanofluids (ESNf) participation. The technical support from Yagmur Polat, Leticia Martinez and Cristina Luengo is highly appreciated.

Conflicts of Interest: The authors declare no conflicts of interest.

\section{References}

1. Vignarooban, K.; Xu, X.; Arvay, A.; Hsu, K.; Kannan, A.M. Heat transfer fluids for concentrating solar power systems-A review. Appl. Energy 2015, 146, 383-396. [CrossRef]

2. Gil, A.; Medrano, M.; Martorell, I.; Lázaro, A.; Dolado, P.; Zalba, B.; Cabeza, L.F. State of the art on high temperature thermal energy storage for power generation. Part 1 -Concepts, materials and modellization. Renew. Sustain. Energy Rev. 2010, 14, 31-55. [CrossRef] 
3. Burgaleta, J.I.; Arias, S.; Ramirez, D. Gemasolar, the first tower thermosolar commercial plant with molten salt storage. Solarpaces 2011, 69, 1-8.

4. Relloso, S.; Delgado, E.B. Experience with molten salt thermal storage in a commercial parabolic trough plant. In Andasol-1 commissioning and operation. In Proceedings of the 15th SolarPACES Symposium, Berlin, Germany, 14-18 September 2009.

5. Bonk, A.; Sau, S.; Uranga, N.; Hernaiz, M.; Bauer, T. Advanced heat transfer fluids for direct molten salt line-focusing CSP plants. Prog. Energy Combust. Sci. 2018, 67, 69-87. [CrossRef]

6. Arthur, O.; Karim, M.A. An investigation into the thermophysical and rheological properties of nanofluids for solar thermal applications. Renew. Sustain. Energy Rev. 2016, 55, 739-755. [CrossRef]

7. Muñoz-Sánchez, B.; Nieto-Maestre, J.; González-Aguilar, J.; Julia, J.E.; Navarrete, N.; Faik, A.; Bauer, T.; Bonk, A.; Navarro, M.E.; Ding, Y.; et al. Round robin test on the measurement of the specific heat of solar salt. AIP Conf. Proc. 2017, 1850, 080017.

8. Muñoz-Sánchez, B.; Nieto-Maestre, J.; Imbuluzqueta, G.; Marañón, I.; Iparraguirre-Torres, I.; García-Romero, A. A precise method to measure the specific heat of solar salt-based nanofluids. J. Therm. Anal. Calorim. 2017, 129, 905-914. [CrossRef]

9. Thoms, M.W. Adsorption at the Nanoparticle Interface for Increased Thermal Capacity in Solar Thermal Systems. Ph.D. Thesis, Massachusetts Institute of Technology, Cambridge, MA, USA, 28 June 2012.

10. Hohne, G.; Hemminger, W.F.; Flammersheim, H.-J. Differential Scanning Calorimetry, 2nd ed.; Springer-Verlag: Heidelberg, Germany, 2003; 298p, Available online: http://www.springer.com/la/book/9783540004677 (accessed on 3 September 2019).

11. Hernaiz, M.; Alonso, V.; Estellé, P.; Wu, Z.; Sundén, B.; Doretti, L.; Mancin, S.; Çobanoğlu, N.; Karadeniz, Z.H.; Garmendia, N.; et al. The contact angle of nanofluids as thermophysical property. J. Colloid Interface Sci. 2019, 547, 393-406. [CrossRef]

12. Lundblad, A.; Bergman, B. Determination of contact angle in porous molten-carbonate fuel-cell electrodes. J. Electrochem. Soc. 1997, 144, 984-987. [CrossRef]

13. Baumli, P.; Kaptay, G. Wettability of carbon surfaces by pure molten alkali chlorides and their penetration into a porous graphite substrate. Mater. Sci. Eng. A 2008, 495, 192-196. [CrossRef]

14. Faik, A.; Grosu, Y.; Udayashankar, N.; González-Fernández, L. Thermal Analysis Sample Container. European Patent application No 18382688.2-1003, 16 April 2019.

15. Grosu, Y.; Udayashankar, N.; Bondarchuk, O.; González-Fernández, L.; Faik, A. Unexpected effect of nanoparticles doping on the corrosivity of molten nitrate salt for thermal energy storage. Sol. Energy Mater. Sol. Cells 2018, 178, 91-97. [CrossRef]

16. Coquard, R.; Panel, B. Adaptation of the FLASH method to the measurement of the thermal conductivity of liquids or pasty materials. Int. J. Therm. Sci. 2009, 48,747-760. [CrossRef]

17. Herminghaus, S. Roughness-induced non-wetting. Europhys. Lett. 2000, 52, 165-170. [CrossRef]

18. Quéré, D. Wetting and roughness. Annu. Rev. Mater. Res. 2008, 38, 71-99. [CrossRef]

19. Liu, T.; Kim, C.J. Turning a surface superrepellent even to completely wetting liquids. Science 2014, 346, 1096-1100. [CrossRef] [PubMed]

20. Takahashi, Y.; Sakamoto, R.; Kamimoto, M. Heat capacities and latent heats of $\mathrm{LiNO}_{3}, \mathrm{NaNO}_{3}$, and $\mathrm{KNO}_{3}$. Int. J. Thermophys. 1988, 9, 1081-1090. [CrossRef]

21. Jriri, T.; Rogez, J.; Bergman, C.; Mathieu, J.C. Thermodynamic study of the condensed phases of $\mathrm{NaNO}_{3}$, $\mathrm{KNO}_{3}$ and $\mathrm{CsNO}_{3}$ and their transitions. Thermochim. Acta 1995, 266, 147-161. [CrossRef]

22. Bradshaw, R.W.; Carling, R.W. A Review of the Chemical and Physical Properties of Molten Alkali Nitrate Salts and Their Effect on Materials Used for Solar Central Receivers; Report SAND87-8005; Sandia National Laboratories: Albuquerque, NM, USA, 1987.

23. Zavoico, A.B. Design Basis Document; SAND2001-2100; Sandia National Laboratories: Albuquerque, NM, USA, 2001.

24. Carling, R.W. Heat capacities of $\mathrm{NaNO}_{3}$ and $\mathrm{KNO}_{3}$ from 350 to 800 K. Thermochim. Acta 1983, 60, $265-275$. [CrossRef]

25. Andreu-Cabelo, P.; Mondragon, R.; Hernandez, L.; Martines-Cuenca, R.; Cabedo, L.; Julia, J.E. Increment of specific heat of Solar Salt with $\mathrm{SiO}_{2}$ nanoparticles. Nanoscale Res. Lett. 2014, 9, 1-9.

26. Schuller, M.; Shao, Q.; Lalk, T. Experimental investigation of the specific heat of a nitrate-alumina nanofluid for solar thermal energy storage systems. Int. J. Therm. Sci. 2015, 91, 142-145. [CrossRef] 
27. Wenzel, R.N. Resistance of solid surfaces to wetting by water. Ind. Eng. Chem. 1936, 28, 988-994. [CrossRef]

28. Cassie, A.B.D.; Baxter, S. Wettability of porous surfaces. Trans. Faraday Soc. 1944, 40, 546-551. [CrossRef]

29. Abdelsalam, M.E.; Bartlett, P.N.; Kelf, T.; Baumberg, J. Wetting of regularly structured gold surfaces. Langmuir 2005, 21, 1753-1757. [CrossRef] [PubMed]

30. Martines, E.; Seunarine, K.; Morgan, H.; Gadegaard, N.; Wilkinson, C.D.; Riehle, M.O. Air-trapping on biocompatible nanopatterns. Langmuir 2006, 22, 11230-11233. [CrossRef] [PubMed]

31. Nithiyanantham, U.; Grosu, Y.; González-Fernández, L.; Zaki, A.; Igartua, J.M.; Faik, A. Corrosion aspects of molten nitrate salt-based nanofluids for thermal energy storage applications. Sol. Energy 2019, 189, $219-227$. [CrossRef]

32. Keene, B.J. Review of data for the surface tension of pure metals. Int. Mater. Rev. 1993, 38, 157-192. [CrossRef]

33. Tricklebank, S.B. Molten Salt Mixtures. IX. The Thermal Conductivities of Molten Nitrate Systems. Aust. J. Chem. 1965, 18, 1171-1176.

34. McDonald, J.; Davis, H.T. Thermal conductivity of binary mixtures of alkali nitrates. J. Phys. Chem. 1970, 74, 725-730. [CrossRef]

35. Omotani, T.; Nagasaka, Y.; Nagashima, A. Measurement of the thermal conductivity of $\mathrm{KNO}_{3}-\mathrm{NaNO}_{3}$ mixtures using a transient hot-wire method with a liquid metal in a capillary probe. Int. J. Thermophys. 1982, 3, 17-26. [CrossRef]

36. Santini, R.; Tadrist, L.; Pantaloni, J.; Cerisier, P. Measurement of thermal conductivity of molten salts in the range $100-500{ }^{\circ} \mathrm{C}$. Int. J. Heat Mass Transf. 1984, 27, 623-626. [CrossRef]

37. Kitade, S.; Kobayashi, Y.; Nagasaka, Y.; Nagashima, A. Measurement of the thermal conductivity of molten $\mathrm{KNO}_{3}$ and $\mathrm{NaNO}_{3}$ by the transient hot-wire method with ceramic-coated probes. High Temp. High Press. $1989,21,219-224$.

38. Grosu, Y.; González-Fernández, L.; Nithiyanantham, U.; Faik, A. Wettability control for correct thermophysical properties determination of molten salts and their nanofluids. In Proceedings of the 1st International Conference on Nanofluids (ICNf), Castello, Spain, 26-28 June 2019.

(C) 2019 by the authors. Licensee MDPI, Basel, Switzerland. This article is an open access article distributed under the terms and conditions of the Creative Commons Attribution (CC BY) license (http://creativecommons.org/licenses/by/4.0/). 